\title{
Intelligence in childhood and chronic widespread pain in middle age: The National Child Development Survey
}

\author{
Catharine R. Gale ${ }^{\mathrm{a}, \mathrm{b}, *}$, Ian J. Deary ${ }^{\mathrm{b}}$, Cyrus Cooper ${ }^{\mathrm{a}}$, G. David Batty ${ }^{\mathrm{b}, \mathrm{c}}$ \\ ${ }^{a}$ MRC Lifecourse Epidemiology Unit, University of Southampton, Southampton, UK \\ ${ }^{\mathrm{b}}$ Centre for Cognitive Ageing and Cognitive Epidemiology, Department of Psychology, University of Edinburgh, Edinburgh, UK \\ ${ }^{\mathrm{c}}$ Department of Epidemiology and Public Health, University College London, London, UK
}

Sponsorships or competing interests that may be relevant to content are disclosed at the end of this article.

\section{A R T I C L E I N F O}

Article history:

Received 6 March 2012

Received in revised form 13 June 2012

Accepted 16 July 2012

\section{Keywords:}

Chronic widespread pain

Intelligence

Cognition

Epidemiology

Longitudinal study

\begin{abstract}
A B S T R A C T
Psychological factors are thought to play a part in the aetiology of chronic widespread pain. We investigated the relationship between intelligence in childhood and risk of chronic widespread pain in adulthood in 6902 men and women from the National Child Development Survey (1958 British Birth Cohort). Participants took a test of general cognitive ability at age 11 years; and chronic widespread pain, defined according to the American College of Rheumatology criteria, was assessed at age 45 years. Risk ratios (RRs) and 95\% confidence intervals (CIs) were estimated using log-binomial regression, adjusting for sex and potential confounding or mediating factors. Risk of chronic widespread pain, defined according to the American College of Rheumatology criteria, rose in a stepwise fashion as intelligence fell ( $P$ for linear trend $<0.0001)$. In sex-adjusted analyses, for an SD lower intelligence quotient, the RR of chronic widespread pain was 1.26 (95\% CI 1.17-1.35). In multivariate backwards stepwise regression, lower childhood intelligence remained as an independent predictor of chronic widespread pain (RR 1.10; $95 \%$ CI 1.01-1.19), along with social class, educational attainment, body mass index, smoking status, and psychological distress. Part of the effect of lower childhood intelligence on risk of chronic widespread pain in midlife was significantly mediated through greater body mass index and more disadvantaged socioeconomic position. Men and women with higher intelligence in childhood are less likely as adults to report chronic widespread pain.
\end{abstract}

(c) 2012 International Association for the Study of Pain. Published by Elsevier B.V. All rights reserved.

\section{Introduction}

Chronic widespread pain (CWP) is a common musculoskeletal problem. Surveys in Europe and the United States show that around $10 \%-15 \%$ of adults have CWP at any time. Prevalence tends to be higher in women and in those from disadvantaged socioeconomic backgrounds, and it rises with age up to about age 70 years $[3,9,24]$. CWP is the major presenting feature of fibromyalgia and one of the commonest reasons for consulting a rheumatologist. Physical factors such as mechanical trauma or the repetitive movements or postures involved in some forms of work are risk factors for CWP [19], but there is also strong evidence that psychological and social factors play a part in its aetiology [7]. Longitudinal studies show that chronic musculoskeletal pain tends to occur more frequently in people with poorer self-rated health and mental

\footnotetext{
* Corresponding author at: MRC Lifecourse Epidemiology Unit, Southampton General Hospital, Southampton SO16 6YD, UK. Tel.: +44 023 80764080; fax: +44 0 2380704021 .

E-mail address: crg@mrc.soton.ac.uk (C.R. Gale).
}

well-being [4], in those with higher levels of psychological distress [25], and independently of this, in those with more severe behaviour problems in childhood [31]. Findings that individuals who report more nonpain somatic symptoms - such as difficulty swallowing, trouble breathing, or frequent vomiting when not pregnant - or who worry more about their health, are at greater risk of developing CWP [27] suggest that this disorder can be a manifestation of the somatisation of distress whereby feelings of distress are thought to be expressed through bodily symptoms.

One psychological factor that could potentially be a risk factor for CWP in adult life is lower cognitive ability in youth. Longitudinal studies of young men enlisted into military service have found that those with lower scores on a test of intelligence at the time they joined up are more likely to be admitted to the hospital with somatoform and neurotic disorders during a 22-year follow-up period [13], and more likely to report having the functional somatic symptom, globus - the persistent sensation of having a lump in one's throat with no detectable physical cause [16]. Another indication that intelligence may be linked with CWP comes from observations in a cohort of people aged 33 to 79 years that lower 
intelligence measured at baseline was associated with a greater number of functional somatic symptoms 1 year later [21]. It is also possible that intelligence in youth could influence risk of CWP indirectly. People who gain lower scores on tests of intelligence in childhood or adolescence are more likely later in life to report symptoms of psychological distress [15] or to be diagnosed with depression or anxiety $[14,26]$, more likely to be overweight or obese and have a history of smoking [1,2], and more likely to be socioeconomically disadvantaged $[1,2]$ - all of which have been associated with CWP $[23,25,39,41]$.

We used data on the National Child Development Survey (1958 British Birth Cohort) to examine the relation between intelligence test scores at the age of 11 years and risk of CWP at age 45 years. Our hypotheses were that men and women who scored lower on the test of intelligence in childhood would have an increased risk of CWP in midlife and that some of this association would be mediated through socioeconomic status, mental health, or lifestyle factors in adulthood.

\section{Methods}

The National Child Development Study was originally based on over 17,000 live births in Great Britain during 1 week in 1958 [33]. The cohort has been followed-up at regular intervals through childhood and adult life. The data on the cohort used in the present study was obtained from the UK Data Archive, University of Essex, UK [36-38].

\subsection{Cognitive ability in childhood}

Cognitive ability was assessed for the first time at school when the children were aged 11 years, using a general ability test devised by the National Foundation for Educational Research in England and Wales [11]. The test consisted of 40 verbal and 40 nonverbal items and was administered by teachers. Scores from this test correlate strongly with scores on a test of verbal ability used to select 11 -year-old children for secondary school $(r=0.93)$, suggesting a high degree of concurrent validity [11]. For ease of interpretation when comparing cognitive ability score according to other characteristics, we transformed scores into intelligence quotient (IQ)-type equivalents, giving the score a mean of 100 and SD of 15 .

\subsection{Chronic widespread pain}

When the cohort members were aged 45 years, they were invited to participate in a biomedical survey. Ethical approval for this study was obtained from the South East Multicentre Research Ethics Committee. Pain was assessed by a self-completion questionnaire. This was the first time detailed data on pain had been collected from cohort members. Participants were asked: "During the past month, have you had any ache or pain that has lasted for one day or longer?" Those who answered positively were asked to shade the location of their pain on 4 blank manikins, representing right side, left side, front, and back of body and to indicate whether they had been aware of the pain for at least 3 months. Based on these data, CWP was defined according to the American College of Rheumatology criteria for fibromyalgia [40] - namely, pain present in the axial skeleton and contralateral body quadrants for at least the past 3 months.

\subsection{Covariates}

We selected father's socioeconomic status at the cohort member's birth, own socioeconomic status, educational attainment, symptoms of psychological distress, body mass index (BMI), and smoking habits as covariates. Previous studies of this cohort have shown that the social class into which a child is born is linked with their subsequent intelligence and with their risk of developing CWP by midlife $[21,24]$, so we viewed this as a potential confounder of any association between childhood intelligence and CWP. Lower intelligence in childhood has been associated with psychological distress [15], obesity, smoking [1,2], and socioeconomic disadvantage in adult life $[1,2]$, and all these latter factors have been linked with CWP $[23,25,39,41]$, so we viewed them as potential mediators of any association between childhood intelligence and CWP.

Father's socioeconomic position was defined using the standard Registrar General's classification of social class [30]-(I) professional, (II) managerial/technical, (IIInm) other non-manual, (IIIm) skilled manual, (IV) partly skilled, and (V) non-skilled-on the basis of his occupation at the birth of the cohort member or, where this information was missing, on the basis of his occupation when the cohort member was aged 7 years. The study member's own socioeconomic position, according to the Registrar General's classification of social class, was based on the participant's occupation, or most recent occupation, as collected at age 42 years. For those participants who were economically inactive at age 42 years (primarily because they were looking after their home and family, sick or disabled, unemployed, or in full-time education), social class was classified according to occupation at age 33 years, or for a small proportion who were economically inactive at that age, occupation at age 23 years. In the sample of 6902 participants on whom our main analyses are based (see below), social class was based on occupation at age 42 years in $88 \%$ of cases, with $10 \%$ based on occupation at age 33 years, and $2 \%$ on occupation at age 23 years.

Data on highest academic qualification were collected at age 42 years and categorized into 6 groups: no qualifications, certificate of secondary education, ordinary levels, advanced levels, sub-degree/diploma, degree, or higher degree. Psychological distress at age 42 years was measured by the 12 -item General Health Questionnaire (GHQ-12) and scored using the Likert method [18]. Participants provided information on their height and weight at age 42 years, from which BMI $\left(\mathrm{kg} / \mathrm{m}^{2}\right)$ was calculated. Cigarette smoking was recorded at age 42 years. Reports of never smoking were verified using self-reported data from ages 23 and 33 years.

\subsection{Supplementary analyses}

To supplement our analyses of childhood intelligence in relation to CWP in midlife, we also examined whether intelligence at age 11 years was related to risk of reporting pain in childhood or earlier in adulthood. For these outcomes we used parental reports from the 11-year survey that the child had recurrent abdominal pain or headache/migraine, teacher reports from the 16-year survey that the child "often complains of aches and pains," and the participants' own reports from the surveys when they were aged 23,33 , and 42 years, that they "often have bad headaches" or "often have backache."

\subsection{Statistical analysis}

We used the $t$-test, $\chi^{2}$ test, and Kruskal-Wallis test to examine differences in baseline characteristics between men and women with and without CWP. We used correlation coefficients to examine the relation between IQ scores and characteristics of the participants. Spearman correlations were used instead of Pearson correlations for characteristics that were categorical or had a skewed distribution. Point bi-serial correlations were used for binary variables. Log-binomial regression was used to examine risk of CWP (or reports of pain earlier in life) for an SD lower IQ score at age 11 years. In order to determine the most parsimonious predic- 
tive model that fitted the data on CWP, we carried out backward stepwise log-binomial regression in which intelligence and all covariates were entered simultaneously in the model predicting CWP and variables with a $P$ value of $\geqslant 0.15$ were successively removed. We used Sobel-Goodman mediation tests to test formally the extent to which mediating variables carried the influence of childhood intelligence to CWP [35].

In total, 9377 cohort members took part in the biomedical survey ( $78 \%$ of the target 11,971 who were invited). Of these, 8497 provided information on CWP, 6902 of whom (81\%) had complete data on intelligence in childhood and the covariates. To investigate possible bias due to missing data, we used multiple multivariate imputation to impute values in any covariates with missing values [34]. Imputation models included childhood intelligence, CWP, the potential confounding and mediating variables, and predictors of dropout from the cohort that had been identified previously [20]. We used switching regression in STATA software (StataCorp, College Station, TX, USA) [34] and carried out 10 cycles of regression switching and generated 10 imputation data sets. The multiple multivariate imputation approach creates a number of copies of the data (in this case, 10 copies), each of which has missing values imputed based on available data and with an appropriate level of randomness using chained equations. The final estimates are obtained by averaging across the estimates from each of these 10 data sets using Rubin's rules and taking into account the uncertainty in the imputation as well as uncertainty due to random variation. Effect sizes obtained after imputation of missing information were essentially the same as those obtained from the sample with complete data, so we present results based on the sample with complete data.

\section{Results}

The prevalence of CWP at age 45 years was $14.4 \%$. Table 1 shows the characteristics of the participants according to the presence or absence of CWP and the correlation of those characteristics with IQ at age 11 years. People who met the criteria for the presence of CWP had scored significantly lower on the test of general mental ability at age 11: there was a 3.1-point difference in IQ between those with CWP and those without it, equivalent to 0.21 of an SD. People with CWP at age 45 years were more likely to have a manual occupational social class background in childhood and as an adult; at the time of the previous follow-up survey at age 42 years, they were more likely to have no academic qualifications, to be a current or ex smoker, to have a higher BMI, and to report greater psychological distress as measured by the GHQ-12. The prevalence of CWP was slightly higher in women, but this difference was not statistically significant. Higher intelligence at age 11 was associated with having a more advantaged social class background in childhood or midlife, greater educational attain- ment, a lower likelihood of ever being a smoker, having a lower $\mathrm{BMI}$, and reporting fewer symptoms of psychological distress at age 42 years.

Fig. 1 shows risk ratios (relative risks) for having CWP according to categories of IQ at age 11 years, using individuals with an IQ of 101 to 110 as the reference group. Risk of having CWP rose in a stepwise fashion as intelligence fell ( $P$ for linear trend $<0.0001$ ).

There was no evidence that associations between intelligence and CWP differed significantly by sex, so men and women were analysed together. In a model adjusting for sex alone, the relative risk of CWP for an SD decrease in intelligence was 1.26 (95\% confidence interval [CI] 1.17-1.35). Table 2 shows the results of backwards stepwise regression of intelligence at age 11 years and all the covariates as predictors of CWP. In these multivariate analyses, of all the variables included initially, intelligence at age 11 years, and the potential mediating factors educational attainment, current social class, BMI, smoking status, and symptoms of psychological distress at age 42 years remained in the final model as independent predictors of CWP. Risk of having CWP at age 45 years increased with more disadvantaged socioeconomic position, being lowest in those in the professional occupational class and highest in the unskilled class. By contrast, there was no clear linear trend between level of educational attainment and risk of CWP; compared to those with a degree, the only group that had a significantly increased risk was those with no academic qualifications. Risk of having CWP was significantly higher in those who 3 years earlier reported more psychological distress as indicated by GHQ-12 scores or who had a higher BMI. (Additional analyses to examine the separate relations between height and weight and risk of CWP found no significant association between height and risk of CWP-for an SD increase in height, the sex-adjusted risk of CWP was 0.99 (95\% CI 0.90 1.09), but greater weight was associated with increased riskfor an SD increase in weight, the sex-adjusted risk of CWP was 1.23 (95\% CI 1.15-1.33).

The effect of childhood intelligence on CWP shrank when social class, educational attainment, BMI, smoking status, and GHQ-12 scores were added to the model: the relative risk of CWP for an SD decrease in intelligence dropped from 1.26 (95\% CI 1.17-1.35) in a sex-adjusted model to 1.10 (95\% CI 1.01-1.19) in the final multivariate model. We carried out a series of Sobel-Goodman mediation tests to examine whether these covariates had significant mediating effects. These tests showed that, after control for the other covariates, neither educational attainment $(P=0.10)$, psychological distress $(P=0.17)$, nor smoking status $(P=0.17)$ had statistically significant mediating effects, but the mediation effects of social class $(P=0.001)$ and BMI $(P<0.0001)$ were both highly significant. Of the total effect of childhood intelligence on risk of CWP at age 45 years, $16 \%$ was mediated through social class and $15 \%$ was mediated through BMI.

Table 1

Characteristics of the study participants according to presence or absence of chronic widespread pain at age 45 years ( $\mathrm{n}=6902$ ).

\begin{tabular}{|c|c|c|c|c|}
\hline & \multicolumn{3}{|c|}{ Chronic widespread pain } & \multirow[t]{2}{*}{ Correlation $^{\mathrm{a}}$ with IQ at age 11 years } \\
\hline & Present $(n=993)$ & Absent $(n=5909)$ & $P$ value & \\
\hline IQ at age 11 years, mean (SD) & $100.3(14.2)$ & $103.4(13.9)$ & $<0.0001$ & - \\
\hline Female, $\mathrm{n}(\%)$ & $515(51.9)$ & $2988(50.6)$ & 0.450 & 0.07 \\
\hline Father in manual social class, $\mathrm{n}(\%)$ & $745(75.0)$ & $4130(70.0)$ & 0.001 & -0.27 \\
\hline No academic qualifications by age $42, \mathrm{n}(\%)$ & $218(23.0)$ & $902(15.3)$ & $<0.0001$ & 0.52 \\
\hline Current or ex-smoker at age 42 years, $n(\%)$ & $605(60.9)$ & $3071(52.0)$ & $<0.0001$ & -0.15 \\
\hline Manual social class, $\mathrm{n}(\%)$ & $449(45.2)$ & $2014(34.8)$ & $<0.0001$ & -0.37 \\
\hline BMI at age 42 years, median (IQR) & $25.8(23.2-28.8)$ & $24.9(22.6-27.7)$ & 0.0001 & -0.11 \\
\hline GHQ-12 score at age 42 years, median (IQR) & $23(21-27)$ & $22(20-24)$ & 0.0001 & -0.05 \\
\hline
\end{tabular}

$\mathrm{IQ}$ = intelligence quotient; $\mathrm{BMI}=$ body mass index; IQR = interquartile range; GHQ-12 = 12-item General Health Questionnaire.

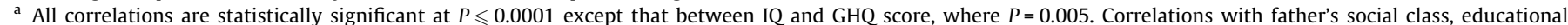
attainment, own social class, and smoking status were calculated using these variables in their original form rather than as binary variables. 


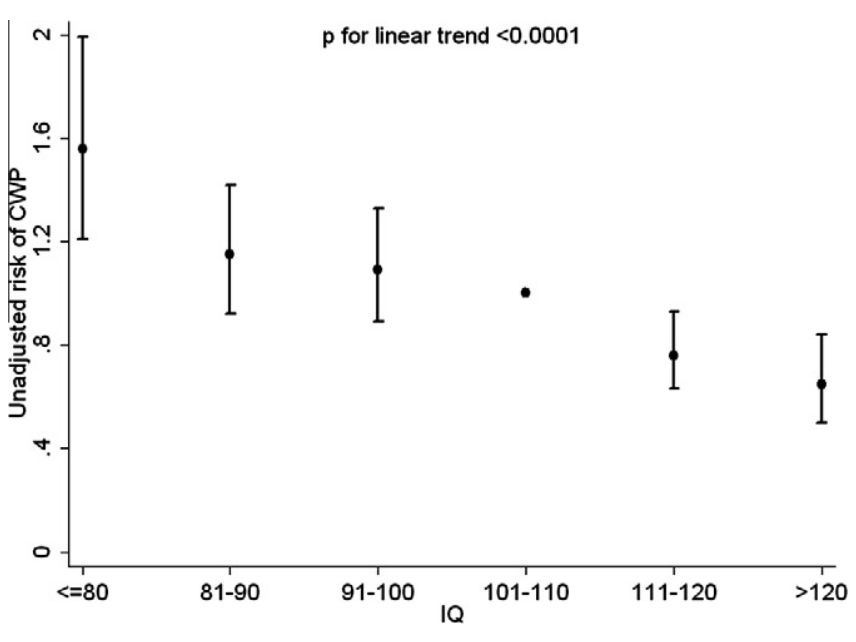

Fig. 1. Unadjusted risk ratios for having chronic widespread pain (CWP) at 45 years in relation to intelligence quotient (IQ) categories at age 11 years. People with an IQ of 101-110 are the reference group.

Table 2

Multivariate model predicting chronic widespread pain at age 45 years $(n=6902)$.

\begin{tabular}{ll}
\hline Variable $^{\mathrm{a}}$ & $\begin{array}{l}\text { Risk ratios (95\% confidence } \\
\text { intervals) }\end{array}$ \\
\hline $\begin{array}{l}\text { IQ at age 11, per SD lower } \\
\text { Social class }\end{array}$ & $1.10(1.01-1.19)$ \\
$\quad$ Professional & 1.0 (Reference) \\
Managerial/technical & $1.27(0.85-1.90)$ \\
Skilled nonmanual & $1.39(0.90-2.13)$ \\
Skilled manual & $1.76(1.15-2.69)$ \\
Partly skilled & $1.66(1.07-2.58)$ \\
Unskilled & $1.90(1.12-3.18)$ \\
Educational attainment by age 42 years & \\
No qualifications & $1.40(1.04-1.89)$ \\
CSE & $1.06(0.78-1.44)$ \\
O level & $1.23(0.96-1.58)$ \\
A level & $1.13(0.83-1.56)$ \\
Subdegree/diploma & $1.37(0.94-1.99)$ \\
Degree or higher degree & $1.0($ Reference) \\
Smoking at age 42 years & \\
Never & $1.0($ Reference) \\
Ex- or occasional smoker & $1.19(1.10-1.40)$ \\
Current smoker & $1.35(1.14-1.61)$ \\
BMI at age 42 years, per SD increase & $1.19(1.12-1.27)$ \\
GHQ-12 score at age 42 years, per SD & $1.41(1.33-1.50)$ \\
increase & \\
\hline
\end{tabular}

IQ = intelligence quotient; CSE = certificate of secondary education; O leve$\mathrm{l}=$ ordinary level; $\mathrm{A}$ level = advanced level; $\mathrm{BMI}=$ body mass index; $\mathrm{IQR}=$ interquartile range; $\mathrm{GHQ}=12$-item General Health Questionnaire.

a These models are the result of stepwise regression starting with all the variables in Table 1 ; variables with $P$ value $\geqslant 0.15$ are removed, leaving the independent predictors shown in the Table.

We examined whether this link between childhood intelligence and pain symptoms was also present earlier in life. After adjustment for sex and father's social class, children whose intelligence was one SD below the mean were more likely at age 11 years ( $n=11,844)$ to have had recurrent abdominal pain or headache/ migraine in the past year, according to their parents (risk ratio [RR] 1.17; 95\% CI 1.10-1.24 and RR 1.22; 95\% CI 1.17-1.28, respectively), and at age 16 years ( $n=9971)$ they were more likely to "often complain of aches and pains" according to their teachers (RR 1.64; 95\% CI 1.52-1.76). After adjustment for sex and current social class, people whose intelligence in childhood was one SD below the mean were more likely at age 23 years $(n=8750)$ to report that they "often had backache" (RR 1.23; 95\% CI 1.16-1.31) or "often had bad headaches" (1.35; 95\% CI 1.26-1.45). Similar associations between childhood intelligence and reports of headache or backache were evident at age 33 years and again at age 42 years. We examined whether the relation between lower childhood intelligence and risk of CWP at age 45 years was concentrated in those who were reported as having recurrent pain by their parents or teachers in childhood. After the exclusion of these individuals, the relation between childhood intelligence and risk of CWP in midlife was little changed.

\section{Discussion}

In this prospective study of 6902 middle-aged men and women, lower intelligence at age 11 years was associated with an increased risk of CWP at age 45 years. The link between lower intelligence in childhood and higher risk of CWP was at least partially statistically mediated through lower socioeconomic position and higher BMI in midlife. Educational attainment, smoking habits, and symptoms of psychological distress did not have significant mediating effects on the association. Additional analyses showed that lower intelligence in childhood was also linked to increased reporting of pain symptoms in childhood and earlier in adulthood.

To our knowledge, this is the first study to investigate the prospective relation between intelligence and CWP. Some cross-sectional studies, mostly small and based on nonrepresentative clinical groups, have shown links between the presence of fibromyalgia and poorer performance on some cognitive domains, particularly working memory and attention [10,17,32]. Recently, a population-based study examined the cross-sectional relation between CWP defined using the American College of Rheumatology criteria and cognitive function in 1539 men aged 40-79 years [22]. The investigators found that men with CWP differed little from those without CWP in performance on tests of visual memory or visuospatial-constructional ability, but had significantly poorer psychomotor processing speed, as measured by the Digit Symbol substitution test, a subtest of the Wechsler Adult Intelligence Scales. These findings have generally been interpreted as suggesting that the experience of chronic pain, or the depression it can induce, has an adverse effect on cognitive function. Experimental data show that increasing pain intensity or fear about pain is linked with greater cognitive deficits among patients with chronic pain [28]. But our observations in the present study suggest that the poorer cognitive performance often reported in people with chronic pain might, in some cases at least, long predate the development of that pain.

Part of the effect of childhood intelligence on risk of CWP was statistically mediated through greater BMI and more disadvantaged socioeconomic position in adult life, but intelligence remained an independent predictor of CWP independently of these factors and other covariates. One possibility is that people with poorer mental abilities may be less able to interpret bodily symptoms correctly [5] and have a heightened sensitivity to the workings of their body. This is consistent with other findings linking lower intelligence to somatoform problems [13,16,21], and with our observations in the present study that the link between lower intelligence and increased pain reporting appears, in some individuals at least, to start early in life. Another possibility is that people with lower intelligence may be less able to apply appropriate coping strategies when faced with pain, increasing the likelihood that it becomes chronic. Evidence in children suggests that those with higher intelligence have a more internal locus of control [12]. Having a greater perception of control over one's life makes people better able to adopt active coping strategies that may reduce pain and disability $[8,29]$. It is also possible that people with lower intelli- 
gence are less able to seek out, understand, and make use of information about pain, perhaps leading to a poorer outcome. Little is known about the relationship between such health literacy skills and CWP, but in qualitative interviews with individuals with chronic low back pain, a recurring theme was the difficulty they experienced finding out and comprehending information about their pain [6].

The main strengths of our study lie in its size, the covariate data, and the availability of a measure of cognitive ability that predated the development of CWP in adulthood, thus avoiding any possibility of reverse causation. The study also has some weaknesses. Firstly, our analyses are based on single measures of both intelligence and CWP. Secondly, we had no data on occupational exposures that have been linked to pain-mechanical factors such as heavy lifting and carrying, extreme flexion of the spine, kneeling, use of vibrating tools-so we were unable to examine whether the greater risk of CWP seen in some participants was explained by these factors. Thirdly, we had no information on use of medical help to deal with pain, so it was not possible to investigate whether people of higher intelligence were more likely to seek medical advice about their symptoms before they became chronic. Fourthly, no data were available on when the CWP started. This means that it is impossible to be certain whether all our potential mediating factors predated the CWP; for instance, the presence of CWP may itself cause psychological distress or lead to weight gain.

In summary, we have presented findings from the first prospective study to examine the relationship between intelligence measured in childhood and CWP in middle age. Our results show that men and women with higher intelligence in childhood are less likely as adults to develop this common and disabling condition. We now need to understand the mechanisms causing this association.

\section{Conflict of interest statement}

The authors have no financial arrangements or conflict of interest to disclose as regards this manuscript. Sponsor's role: none.

\section{Acknowledgments}

The Centre for Cognitive Ageing and Cognitive Epidemiology is funded by the Biotechnology Sciences Research Council, the Engineering and Physical Sciences Research Council, the Economic and Social Research Council, the Medical Research Council, and the University of Edinburgh as part of the cross-council Lifelong Health and Wellbeing initiative (G0700704/84698). David Batty is a Wellcome Trust Fellow. We are grateful to the UK Data Archive for providing the data. The original data collectors, the funders of the data collection and the UK Data Archive bear no responsibility for the analyses and interpretation presented here.

\section{References}

[1] Batty GD, Deary IJ, Schoon I, Gale CR. Mental ability across childhood and risk factors for premature mortality in adult life: the 1970 British Cohort Study. J Epidemiol Community Health 2007;61:997-1003.

[2] Batty GD, Shipley MJ, Mortensen LH, Boyle SH, Barefoot J, Gronbaek M, Gale CR, Deary IJ. IQ in late adolescence/early adulthood, risk factors in middle age and later all-cause mortality in men: the Vietnam Experience Study. J Epidemiol Community Health 2008;62:522-31.

[3] Bergman S, Herrstrom P, Hogstrom K, Petersson IF, Svensson B, Jacobsson LT. Chronic musculoskeletal pain, prevalence rates, and sociodemographic associations in a Swedish population study. J Rheumatol 2001;28:1369-77.

[4] Bergman S, Jacobsson LT, Herrstrom P, Petersson IF. Health status as measured by SF-36 reflects changes and predicts outcome in chronic musculoskeletal pain: a 3-year follow up study in the general population. PAIN ${ }^{\circledR} 2004 ; 108$ : 115-23.

[5] Bogaerts K, Van EL, Li W, Bresseleers J, Van DI, De PS, Stans L, Decramer M, Van den Bergh O. Distorted symptom perception in patients with medically unexplained symptoms. J Abnorm Psychol 2010;119:226-34.
[6] Briggs AM, Jordan JE, Buchbinder R, Burnett AF, O'Sullivan PB, Chua JY, Osborne $\mathrm{RH}$, Straker LM. Health literacy and beliefs among a community cohort with and without chronic low back pain. PAIN ${ }^{\circledR} 2010 ; 150: 275-83$.

[7] Clauw DJ, Crofford LJ. Chronic widespread pain and fibromyalgia: what we know, and what we need to know. Best Pract Res Clin Rheumatol 2003;17:685-701.

[8] Crisson JE, Keefe FJ. The relationship of locus of control to pain coping strategies and psychological distress in chronic pain patients. PAIN ${ }^{\circledR}$ 1988;35:147-54.

[9] Croft P, Rigby AS, Boswell R, Schollum J, Silman A. The prevalence of chronic widespread pain in the general population. J Rheumatol 1993;20:710-3.

[10] Dick BD, Verrier MJ, Harker KT, Rashiq S. Disruption of cognitive function in fibromyalgia syndrome. PAIN ${ }^{\circledR}$ 2008;139:610-6.

[11] Douglas J. The home and the school. A study of ability and attainment in the primary school. London: MacGibbon \& Kee; 1964.

[12] Gale CR, Batty GD, Deary IJ. Locus of control at age 10 years and health outcomes and behaviors at age 30 years: the 1970 British Cohort Study. Psychosom Med 2008;70:397-403.

[13] Gale CR, Batty GD, Tynelius P, Deary IJ, Rasmussen F. Intelligence in early adulthood and subsequent hospitalisation and admission rates for the whole range of mental disorders: longitudinal study of 1049,663 men. Epidemiology 2010;21:70-7.

[14] Gale CR, Deary IJ, Boyle SH, Barefoot J, Mortensen LH, Batty GD. Cognitive ability in early adulthood and risk of five specific psychiatric disorders in mid life: the Vietnam Experience Study. Arch Gen Psychiatry 2008;65:1410-8.

[15] Gale CR, Hatch SL, Batty GD, Deary IJ. Intelligence in childhood and risk of psychological distress in adulthood: the 1958 National Child Development Survey and the 1970 British Cohort Study. Intelligence 2009;37:592-9.

[16] Gale CR, Wilson JA, Deary IJ. Globus sensation and psychopathology in men: the Vietnam experience study. Psychosom Med 2009;71:1026-31.

[17] Glass JM. Review of cognitive dysfunction in fibromyalgia: a convergence on working memory and attentional control impairments. Rheum Dis Clin North Am 2009;35:299-311.

[18] Goldberg DP, Williams P. A user's guide to the General Health Questionnaire. Windsor, UK: Nfer-Nelson; 1988.

[19] Harkness EF, Macfarlane GJ, Nahit E, Silman AJ, McBeth J. Mechanical injury and psychosocial factors in the work place predict the onset of widespread body pain: a two-year prospective study among cohorts of newly employed workers. Arthritis Rheum 2004;50:1655-64.

[20] Hawkes D, Plewis I. Modelling non-response in the National Child Development Study. J R Stat Soc Ser A: Stat Soc 2006;169:479-91.

[21] Kingma EM, Tak LM, Huisman M, Rosmalen JG. Intelligence is negatively associated with the number of functional somatic symptoms. J Epidemiol Community Health 2009;63:900-5.

[22] Lee DM, Pendleton N, Tajar A, O'Neill TW, O'Connor DB, Bartfai G, Boonen S, Casanueva FF, Finn JD, Forti G, Giwercman A, Han TS, Huhtaniemi IT, Kula K, Lean MEJ, Punab M, Silman AJ, Vanderschueren D, Moseley CM, Wu FCW, McBeth J. Chronic widespread pain is associated with slower cognitive processing speed in middle-aged and older European men. PAIN ${ }^{\circledR}$ 2010;151:30-6.

[23] Macfarlane GJ, Norrie G, Atherton K, Power C, Jones GT. The influence of socioeconomic status on the reporting of regional and widespread musculoskeletal pain: results from the 1958 British Birth Cohort Study. Ann Rheum Dis 2009;68:1591-5.

[24] Macfarlane GJ, Pye SR, Finn JD, Wu FC, Silman AJ, Bartfai G, Boonen S, Casanueva F, Forti G, Giwercman A, Han TS, Huhtaniemi IT, Kula K, Lean ME, O'Neill TW, Pendleton N, Punab M, Vanderschueren D. Investigating the determinants of international differences in the prevalence of chronic widespread pain: evidence from the European Male Ageing Study. Ann Rheum Dis 2009;68:690-5.

[25] Magni G, Moreschi C, Rigatti-Luchini S, Merskey H. Prospective study on the relationship between depressive symptoms and chronic musculoskeletal pain. PAIN $^{\circledR}$ 1994;56:289-97.

[26] Martin LT, Kubzansky LD, Lewinn KZ, Lipsitt LP, Satz P, Buka SL. Childhood cognitive performance and risk of generalized anxiety disorder. Int J Epidemiol 2007;36:769-75.

[27] McBeth J, Macfarlane GJ, Benjamin S, Silman AJ. Features of somatization predict the onset of chronic widespread pain: results of a large populationbased study. Arthritis Rheum 2001;44:940-6.

[28] Moriarty O, McGuire BE, Finn DP. The effect of pain on cognitive function: a review of clinical and preclinical research. Prog Neurobiol 2011;93:385-404.

[29] Nes LS, Roach AR, Segerstrom SC. Executive functions, self-regulation, and chronic pain: a review. Ann Behav Med 2009;37:173-83.

[30] Office for National Statistics. Standard occupational classification. London: HMSO; 2000.

[31] Pang D, Jones GT, Power C, Macfarlane GJ. Influence of childhood behaviour on the reporting of chronic widespread pain in adulthood: results from the 1958 British Birth Cohort Study. Rheumatology (Oxford) 2010;49:1882-8.

[32] Park DC, Glass JM, Minear M, Crofford LJ. Cognitive function in fibromyalgia patients. Arthritis Rheum 2001;44:2125-33.

[33] Power C, Elliott J. Cohort profile: 1958 British birth cohort (National Child Development Study). Int J Epidemiol 2006;35:34-41.

[34] Royston P. Multiple imputation of missing values. Stata J 2004;4:227-41.

[35] Sobel ME. Asymptotic confidence intervals for indirect effects in structural equation models. In: Leinhart S, editor. Sociological methodology. San Francisco: Jossey-Bass; 1982. p. 290-312. 
[36] University of London. Institute of Education. Centre for Longitudinal Studies, National Child Development Study: Childhood Data, Sweeps 0-3, 1958-1974 [computer file]. 2nd Edition. National Birthday Trust Fund, National Children's Bureau, [original data producer(s)]. Colchester, Essex: UK Data Archive [distributor], August 2008. SN: 5565, http://dx.doi.org/10.5255/UKDA-SN5565-1.

[37] University of London. Institute of Education. Centre for Longitudinal Studies, National Child Development Study: Sweep 6, 1999-2000 [computer file]. 2nd Edition. Joint Centre for Longitudinal Research, [original data producer(s)]. Colchester, Essex: UK Data Archive [distributor], August 2008. SN: 5578, http://dx.doi.org/10.5255/UKDA-SN-5578-1.

[38] University of London. Institute of Education. Centre for Longitudinal Studies, National Child Development Study: Biomedical Data, 2002-2004: Special Licence Access [computer file]. Colchester, Essex: UK Data Archive [distributor], January 2009. SN: 5594, http://dx.doi.org/10.5255/UKDA-SN5594-1.

[39] Vandenkerkhof EG, Macdonald HM, Jones GT, Power C, Macfarlane GJ. Diet, lifestyle and chronic widespread pain: results from the 1958 British Birth Cohort Study. Pain Res Manag 2011;16:87-92.

[40] Wolfe F, Smythe HA, Yunus MB, Bennett RM, Bombardier C, Goldenberg DL, Tugwell P, Campbell SM, Abeles M, Clark P, Fam AG, Farber SJ, Fiechtner JJ, Franklin CM, Gatter RA, Hamaty D, Lessard J, Lichtbroun AS, Masi AT, Mccain GA, Reynolds WJ, Romano TJ, Russell IJ, Sheon RP. The American College of Rheumatology 1990 Criteria for the Classification of Fibromyalgia - report of the Multicenter Criteria Committee. Arthritis Rheum 1990;33:160-72.

[41] Wright LJ, Schur E, Noonan C, Ahumada S, Buchwald D, Afari N. Chronic pain, overweight, and obesity: findings from a community-based twin registry. J Pain 2010;11:628-35 